\title{
Energy Absorption
}

National Cancer Institute

\section{Source}

National Cancer Institute. Energy Absorption. NCI Thesaurus. Code C45995.

The process in which radiated energy is partially or completely retained in the matter which it traverses. 